\title{
Low Dosages of Interleukin 1 Protect Mice against Lethal Cerebral Malaria
}

\author{
By Jo H. A. J. Curfs, ${ }^{*}$ Jos W. M. van der Meer, $\ddagger$ \\ Robert W. Sauerwein," and Wynand M. C. Eling*
}

From the Departments of *Medical Microbiology and $\$$ Intermal Medicine, Faculty of Medicine,

Catholic University of Nijmegen, $6500 \mathrm{HB}$ Nijmegen, The Netherlands

\begin{abstract}
Summary
In cerebral malaria, pathological changes can be found in the brain of infected people and in the brain of Plasmodium berghei-infected mice. The pathogenesis of cerebral malaria in mice is believed to be due to an immunopathological reaction giving rise to an excessive production of cytokines such as interferon $\gamma($ IFN- $\gamma$ ) and tumor necrosis factor (TNF). We find that low doses of interleukin 1 (IL-1) protect mice against cerebral malaria; II-1 also inhibits parasitemia. The IL-1 effect on parasitemia was not observed in nude mice and was at least partly reversed in mice treated with IL-1 in combination with antibody to IFN- $\gamma$, indicating the involvement of $\mathrm{T}$ cells. Mice protected against development of cerebral malaria by IL-1 treatment developed the syndrome when TNF was given as observed in control infected mice or infected mice treated with inactivated IL-1.
\end{abstract}

$\mathrm{C}$ erebral malaria is an important cause of death in people infected with the human malaria parasite Plasmodium falciparum (1). In a proportion of patients that die from cerebral malaria, inflammatory cells, loss of endothelial wall integrity, and hemorrhages are found in the brain at autopsy $(2,3)$. The pathogenesis of human cerebral malaria, including that of the hemorrhages, is largely unexplained.

Similar findings are obtained in a murine malaria model after infection with $P$. berghei $(4,5)$. Infection with this rodent malaria parasite can lead to the development of hemorrhages in the brains of hamsters (6), young rats (unpublished observations), and mice $(4,5,7)$. In P. berghei-infected mice, the development of the hemorrhages coincides with a sudden and irreversible decrease of the body temperature followed by rapid death (5). There are indications that a $T$ cell-dependent immunopathological reaction and excessive production of cytokines, particularly IFN- $\gamma$ and TNF- $\alpha$, play an important role in the pathogenesis of the brain hemorrhages in infected mice $(5,8)$. Detrimental and even lethal effects of cytokines, such as TNF, have also been described in Gramnegative bacterial infections and endotoxemias (9). There are, however, beneficial effects of cytokines too. The cytokine II-1, administered in a low dose to mice, appears to protect mice from lethal infections due to bacteria such as Pseudomonas aeruginosa, Klebsiella pneumoniae, Listeria monocytogenes, and fungi such as Candida albicans (10-14). Although the mechanism of protection has not yet been elucidated, it is an important question whether similar protection can be obtained against a parasitic disease such as lethal cerebral malaria. Therefore, and because of the strong functional relationship between
TNF and IL-1 (15), the effect of low dosages of human rIL $1 \alpha$ and rIL-1 $\beta$ was investigated in lethal $P$. berghei infection in $\mathrm{C} 57 \mathrm{Bl} / 6 \mathrm{~J}$ mice.

Low-dose IL-1 treatment inhibited parasite proliferation in a dose-dependent way, but only in intact mice, not in $T$ cell-deficient nude mice. Independent of this effect on parasite proliferation, IL-1 treatment prevented development of cerebral malaria.

Excessive TNF release is assumed to be responsible for most of the pathology associated with malaria (16), and exogenous TNF given during infection can accelerate the development of the cerebral syndrome. IL-1 treatment, however, did not protect against this TNF-accelerated development of cerebral malaria in $P$. berghei-infected mice.

\section{Materials and Methods}

Mice. C57Bl/6J mice were obtained from a local colony and housed under specific pathogen-free conditions with food (Hope Farms, Woerden, The Netherlands) and water ad libitum.

Parasite. P. berghei K173 was maintained by weekly transfer of parasitized erythrocytes (PE) from infected to naive mice. Experimental mice were infected with $1,000 \mathrm{PE}$ intraperitoneally.

Parasitemia. Thin blood films were made from tail blood and stained with May-Grünwald and Giemsa's solutions.

Body Temperature. To measure body temperature, the probe of a digital thermometer (Technoterm; Thermotex, The Hague, The Netherlands) was inserted in the rectum and read after $18 \mathrm{~s}$.

Light and electron microscopy of brain tissue using routine histological procedures was carried out to detect the presence of hemorrhages. 
Interleukin 1. Human rIL-1 $\alpha$ was obtained from Dr. P. Lomedico (Hoffmann-La Roche, Inc., Nutley, NJ). Human rIL-1 $\beta$ was obtained from Dr. Alan Shaw (Glaxo, Geneva).

Recombinant TNF- $\alpha$ was obtained from Dr. G. R. Adolf, Ernst Boehringer Institute, Vienna, Austria.

Anti-IFN- $\gamma$ Antibody. mAb (DB-9) against mouse IFN- $\gamma$ was obtained from Dr. P.H. van der Meide (T.N.O., Rijswijk, The Netherlands).

\section{Results and Discussion}

Various II-1 treatments were given to infected mice. When $80 \mathrm{ng}$ of IL-1 $\alpha$ was given intraperitoneally for six consecutive days, starting on the day of infection, $78 \%$ of the mice were protected against cerebral malaria and experienced only a limited and transient change in body temperature (Fig. 1 $A$ ), whereas all mice that received heat-inactivated II- $1 \alpha$ $\left(100^{\circ} \mathrm{C}\right.$ for $20 \mathrm{~min}$ ) developed lethal cerebral malaria (Fig. $1 A$ and 2). In addition, a remarkable delay of the development of the parasitemia was observed in mice treated with IL-1 (Fig. 1 B). Although at day 12 parasitemia in IL-1-treated mice became as high as in control mice at day 7 (control mice were treated with inactivated II-1), no dramatic decrease in body temperature and no cerebral hemorrhages occurred in the IL-1-treated group. Increasing daily dosages up to 320 ng IL-1 showed a further delay in the development of the parasitemia and again prevented development of cerebral malaria (Fig. 3). It was found that a single intraperitoneal injection of $80 \mathrm{ng}$ IL-1 $\alpha$ given $3 \mathrm{~d}$ after an intravenous infection with 1,000 parasites prevented death from cerebral bleedings in $50 \%(n=10)$ of the animals. In addition, in all mice treated with II-1 on day 3 of infection, the course of the parasitemia was the same and independent of development of cerebral malaria. This makes it unlikely that protection against cerebral malaria by IL-1 treatment is due to its effect on parasitemia. IL-1 given as a single injection at day $0(n=5)$ or day $5(n=5)$ did not have an effect on parasitemia and did not prevent cerebral malaria. Perhaps a more important observation was that IL-1 given shortly before the development of the cerebral syndrome, i.e., on day $8(n=10)$, also did not affect the development of the syndrome. Comparable experiments using a 6-d treatment with IL-1 $\beta$ again showed protection against cerebral malaria and inhibition of parasitemia. Furthermore, implantation of osmotic pumps containing IL-1 $\alpha 2 \mathrm{~d}$ before infection (calculated dose, $80 \mathrm{ng}$ IL-1/24 h; pumps active for $20 \mathrm{~d}$ ) did have a similar effect on parasitemia and protected against the development of cerebral malaria, as did the 6-d treatment where II-1 was injected daily $(n=5)$. Inhibition of the proliferation of the parasite and protection against cerebral malaria were seen as the main effects from the various II-1 treatments.

Based on these observations, a series of experiments was performed in order to determine a possible mechanism of action of IL-1. First, it is known that parasite proliferation is strongly dependent on erythropoietic activity, probably related to the parasite's preference for reticulocytes (17), and IL-1 can suppress erythropoietin activity in vitro (18), though its effect in vivo is less clear (18). Therefore, it was investigated whether
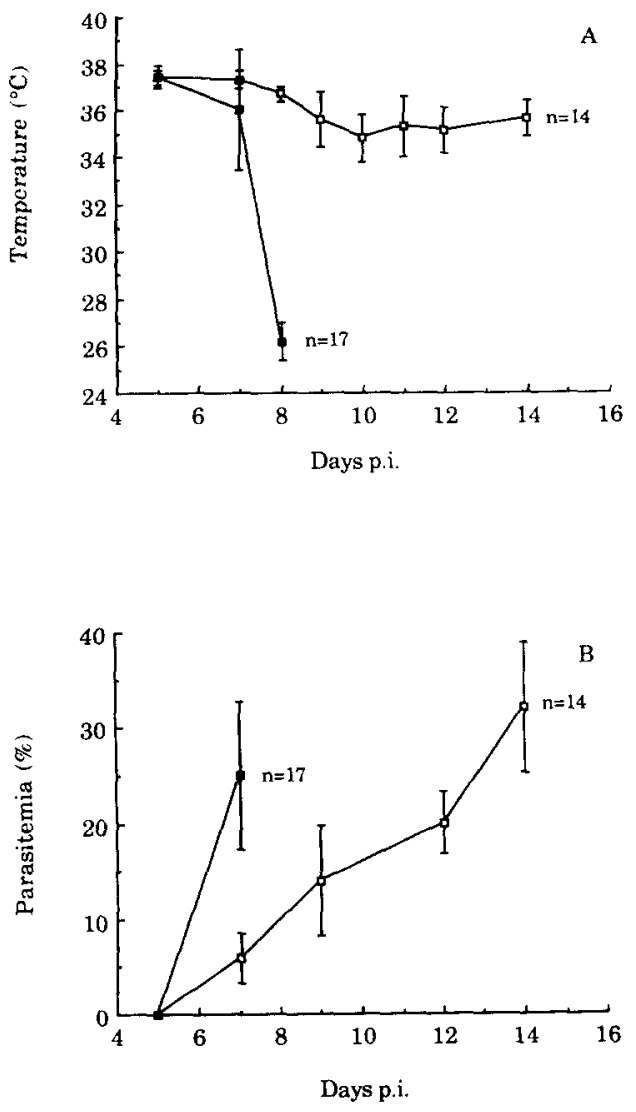

Figure 1. Effect of IL-1 treatment on $P$. berghei infection in C57Bl/6] mice. Mice were infected with 1,000 parasites intravenously. From day 0 to 5 mice received $80 \mathrm{ng}$ of IL-1 (D) or inactivated IL-1 (D) intraperitoneally daily. Summarized results from four independent experiments. SD of the mean is indicated as error bars.

or not IL-1 treatment suppresses erythropoiesis, thereby limiting parasitemia. Erythropoiesis was enhanced by letting 12 drops of blood from the retro-orbital plexus through a hematocrit capillary $1 \mathrm{~d}$ before IL 1 treatment. $3 \mathrm{~d}$ after bleeding increased, reticulocyte counts were obtained (untreated controls: $1.2 \pm 0.3 \% ; n=5$ ), but no difference was found between mice treated with IL-1 $(5.3 \pm 2.1 \% ; n=6)$ or inactivated $\mathrm{I}-1(5.3 \pm 3.3 \% ; n=3) .6 \mathrm{~d}$ after bleeding, reticulocyte counts had returned to normal values.

Second, since mouse studies have shown that T lymphocytes play an essential role in the immunopathology of malaria $(5,10)$, we investigated whether IL-1 could influence parasitemia in $\mathrm{C} 57 \mathrm{Bl} / 6 \mathrm{~J}$ nude mice (no cerebral malaria in $\mathrm{T}$ cell-deficient mice) Parasitemia was not influenced by IL-1 in these T cell-deficient animals (Fig. 4). Thus, a direct effect on parasite proliferation is highly unlikely since IL-1 is not effective against parasitemia in nude mice. Apparently, $\mathrm{T}$ lymphocytes or products of these cells are involved in this process, either by specific or nonspecific immunological effects on the parasite. The fact that the action of IL-1 on the proliferation of the parasite is observed early during infection would be in favor of a nonspecific effect on the parasite, e.g., via 

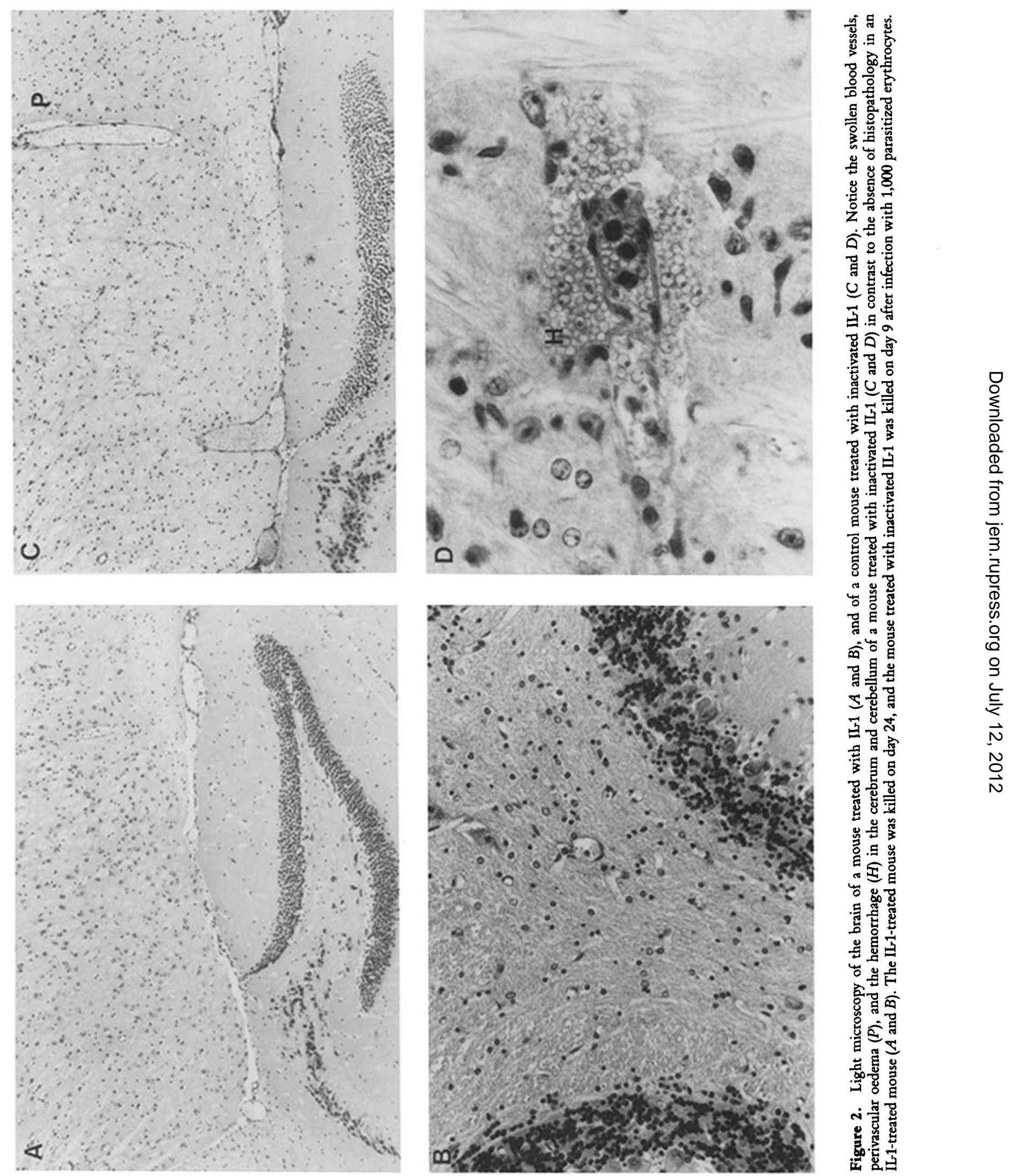

焉造要

政

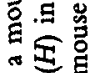

पै

趋焉

步

岁美

合苟穴

政

总要总

语焉 


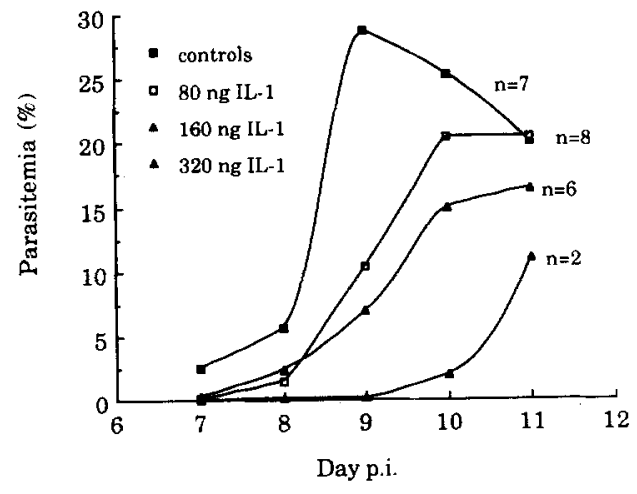

Figure 3. Effect of increasing doses of IL-1 given from day 0 to 5 on parasitemia. $\mathrm{C} 57 \mathrm{Bl} / 6 \mathrm{~J}$ mice were infected with 1,000 parasitized erythrocytes on day 0 .

the release of lymphokines such as IFN- $\gamma(19)$. Indeed, when infected mice were treated with a combination of IL-1 (80 $\mathrm{ng} / \mathrm{mouse} / \mathrm{d}$ for $6 \mathrm{~d}$ ) and anti-IFN- $\gamma$ antibody $(1 \mathrm{mg} / \mathrm{mouse}$ $1 \mathrm{~d}$ before and $6 \mathrm{~d}$ after infection), the suppressive effect of IL-1 on parasitemia was reversed: $8 \mathrm{~d}$ after infection, parasitemia in IL-1-treated mice was $3.3 \pm 3.2 \%(n=3)$, and in mice treated with IL-1 and antibody to IFN- $\gamma, 7.3 \pm 0.9 \%$ $(n=3)(p>0.06)$; parasitemia in untreated mice was still higher $(15.7 \pm 4.1 \% ; n=3)$. IL-1 protection against the development of cerebral malaria, however, was not reversed when antibody to IFN- $\gamma$ was added to the treatment. Treatment of infected mice with antibody against IFN- $\gamma$ without IL-1 had no effect on parasitemia (results not shown). These data support the hypothesis that IL-1-dependent suppression of parasitemia is at least partly mediated by an IL-1-induced release of IFN- $\gamma$ from $\mathrm{T}$ cells.

Specific immunological effects induced by II-1 are not ruled out; IL-1 can lead to enhanced production of antibodies (20), which can contribute to the prevention of the cerebral syndrome. Timely treatment with IgG from malaria-immune mice prevents severe hypothermia as well as the development of hemorrhages under conditions, where there is no effect on the course of the parasitemia, indicating that specific antibodies can protect against cerebral malaria (5).

According to our data protection against cerebral malaria and delayed parasitemia are not linked. This is in agreement

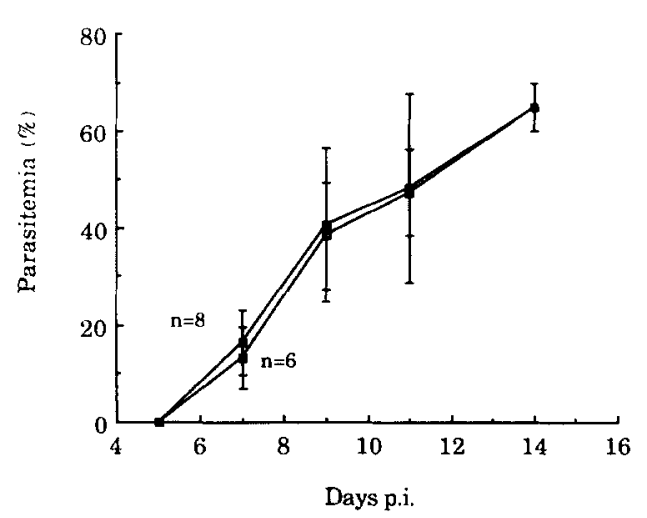

Figure 4. Effect of IL-1 treatment on $P$. berghei infection in $\mathrm{C} 57 \mathrm{Bl} / 6 \mathrm{~J}$ nude mice. $2 \mathrm{~d}$ before infection with 1,000 parasitized erythrocytes, osmotic pumps (2002; Alza Corp., Palo Alto, CA) were implanted intraperitoneally containing either IL-1 ( $\square$ ) or inactivated IL-1 ( $\square$ ). Calculated IL-1 dosage, $80 \mathrm{ng}$ IL-1/24 h. Pumps were operational for $20 \mathrm{~d}$. Shown are summarized results of two independent experiments. SEM is indicated as error bars.

with experiments in lethal Gram negative infection; in these studies survival was not due to increased microbicidal mechanisms $(9,10)$. A hypothesis that came from those studies was that pretreatment with IL-1 interfered with the lethal effects of cytokines such as TNF (10) e.g., by modulating the receptors for this latter cytokine or by another mechanism of desensitization (21). A similar mechanism of protection could be operational here. The work of Grau et al. (7) and Clark (22) suggests that TNF plays a pivotal role in the development of lethal malaria. Therefore it was investigated whether IL-1 would protect against the accelerated development of cerebral malaria of $P$. berghei-infected mice by injection of exogenous TNF. Mice were infected with 1000 parasites and were treated for five days with IL -1 or inactivated IL-1. On day 5 or later these mice were injected with $15 \mu \mathrm{g}$ rec. human TNF. Within a few hours after injection of TNF, both IL 1 treated mice as well as control mice became hypothermic and died with cerebral hemorrhages. Uninfected mice injected with the same dose of TNF did not exhibit a decrease in body temperature and did not die. These results argue against the possibility that protection against cerebral malaria induced by IL-1 is due to a decreased sensitivity to TNF.

Address correspondence to Jos W. M. van der Meer, Department of Internal Medicine, Catholic University of Nijmegen, Geert Grooteplein 8, P.O. Box 9101, 6500 HB Nijmegen, The Netherlands.

Received for publication 30 April 1990 and in revised form 23 July 1990.

\section{References}

1. Daroff, R.B., J.J. Deller, A.J. Kast, and W.W. Blocker. 1967. Cerebral malaria. J. Am. Med. Assoc. 202:679.

2. Maegraith, B.G. 1948. Pathological Processes in Malaria and
Blackwater Fever. Blackwell Scientific Publications Ltd., Oxford. 260-289.

3. Marsden, P.D., L.J. Bruce-Chwatt. 1975. Cerebral malaria. In 
Topics in Tropical Neurology. Vol. 12 of Contemporary Neurology Series. R.W. Hornabrook, editor. Davis Company, Philadelphia. 29-94.

4. Rest, J.R. 1982. Cerebral malaria in inbred mice. I. A new model and its pathology. Trans. R. Soc. Trop. Med. Hyg. 76:410.

5. Curfs, J.H.A.J., T.P.M. Schetters, C.C. Hermsen, C.R. Jerusalem, A.A.J.C. Van Zon, and W.M.C. Eling. 1989. Immunological aspects of cerebral lesions in murine malaria. Clin. Exp. Med. 75:136.

6. Wright, D.H., R.M. Masembe, and E.R. Bazira. 1971. The effect of antithymocyte serum on golden hamsters and rats infected with Plasmodium berghei. Br. J. Exp. Pathol. 52:465.

7. Grau, G.E., P.-F. Piguet, H.D. Engers, J.A. Louis, P. Vassali, and P.-H. Lambert. 1986. L3T4 ${ }^{+}$T-lymphocytes play a major role in the pathogenesis of murine cerebral malaria. J. Immunol. 137:2348.

8. Grau, G.E., V. Kindler, P.-F. Piguet, P.-H. Lambert, and P. Vassali. 1988. Prevention of experimental cerebral malaria by anticytokine antibodies. J. Exp. Med. 168:1499.

9. Beutler, B., N. Krochin, I.W. Milsark, D. Leudke, and A. Cerami. 1986. Control of cachectin (tumor necrosis factor) synthesis: mechanisms of endotoxin resistance. Science (Wash. DC). 232:977.

10. Van der Meer, J.W.M., M. Barza, S.M. Wolf, and C.A. Dinarello. 1988. A low dose of recombinant Interleukin-1 protects granulocytopenic mice from lethal Gram-negative infection. Proc. Natl. Acad. Sci. USA. 85:1620.

11. Van der Meer, J.W.M. 1988. The effects of recombinant interleukin-1 and recombinant tumor necrosis factor on nonspecific resistance to infection. Biotherapy. 1:19.

12. Ozaki, Y., T. Ohashi, A. Minami, and S.-I. Nakamura. 1987. Enhanced resistance of mice to bacterial infection induced by recombinant human interleukin-1 $\alpha$. Infect. Immun. 55:1436.
13. Czuprinsky, C.J., and J.F. Brown. 1987. Recombinant human interleukin-1 $\alpha$ enhancement of non-specific antibacterial resistance. Infect. Immun. 55:2061.

14. Van't Wout, J.W., J.W.M. Van der Meer, M. Barza, and C.A. Dinarello. 1988. Protection of neutropenic mice from lethal Candida albicans infection by recombinant interleukin-1. Eur. J. Immunol. 18:1143.

15. Le, J., and J. Vilcek. 1987. Biology of disease. Tumor necrosis factor and interleukin-1: cytokines with multiple overlapping biological activities. Lab. Invest. 56(3):234.

16. Clark, I.A., W.B. Cowden, G.A. Butcher, and N.H. Hunt. 1987. Possible roles of tumor necrosis factor in the pathology of malaria. Am. J. Pathol. 129:192.

17. Hejna, J.M., N.J. Rencricca, and R.M. Coleman. 1974. Effective recovery and immunity to virulent malaria following red cell transfusion at crisis. Proc. Soc. Exp. Biol. Med. 46:462.

18. Schooley, J.C., B. Kullgren, and A.C. Allison. 1987. Inhibition by Interleukin- 1 of the action of erythropoietin on erythroid precursors and its possible role in the pathogenesis of hypoplastic anaemias. Br. J. Haematol. 67:11.

19. Clark, I.A., N.H. Hunt, G.A. Butcher, and W.B. Cowden. 1987. Inhibition of murine malaria (Plasmodium chabaudi) in vivo by recombinant interferon- $\gamma$ or tumor necrosis factor, and its enhancement by butylated hydroxyanisole. J. Immunol. 139:3493.

20. Staruch, M.J., and D.D. Wood. 1983. The adjuvanticity of interleukin-1 in vivo. J. Immunol. 130:2192.

21. Wallach, D., H. Holtmann, H. Engelmann, and Y. Nophar. 1988. Sensitisation and desensitisation to lethal effects of tumor necrosis factor and IL-1. J. Immunol. 140:2994.

22. Clark, I.A. 1987. Monokines and lymphokines in malarial pathology. Ann. Trop. Med. Parasitol. 81:577. 